\title{
Keine Staatsintervention mit der Volksinitiative «la zur Hausarztmedizin»!
}

Peter Tschudi ${ }^{a}$
Heinrich Koller ${ }^{b}$,
Thomas Gächter $^{c}$

a Prof. Dr. med., Präsident Initiativkomitee «Ja zur Hausarztmedizin», Vorsteher Institut für Hausarztmedizin Basel (IHAMB)

b Prof. Dr. iur. et lic. oec. a. o. Professor für öffentliches Recht an der Juristischen Fakultät Basel

c Prof. Dr. iur., Lehrstuhlinhaber für Staats-, Verwaltungs- und Sozialversicherungsrecht der Universität Zürich
1 Cassis I. Ist der Arztberuf noch ein freier Beruf? Schweiz Ärztezeitung. 2010 91(10):385-6

Korrespondenz: Prof. Dr. med. Peter Tschudi Praxis Hammer Bläsiring 160 CH-4057 Basel
Es gilt zunächst festzuhalten, dass Ignazio Cassis in eigenem Namen schreibt und seine persönliche Meinung vertritt. Es handelt sich also weder um ein Editorial der Schweizerischen Ärztezeitung noch um eine offizielle Stellungnahme der FMH. Im Gegensatz zu Ignazio Cassis unterstützt die FMH die Initiative «Ja zur Hausarztmedizin».

Der Initiativtext wurde in enger Zusammenarbeit mit den Professoren Dr. Heinrich Koller, ehemaliger Direktor des Bundesamtes für Justiz und Advokat, Dr. Thomas Gächter, Inhaber des Lehrstuhls für Staats-, Verwaltungs- und Sozialversicherungsrecht an der Universität Zürich, und Dr. Thomas Poledna, Rechtsanwalt und Dozent in Zürich, ausgearbeitet - also mit Fachexperten, die ganz oder teilweise ebenfalls Freiberufler und dem liberalen Gedankengut verpflichtet sind. Weder ihnen noch den Initianten geht es um mehr Staatsintervention. Ziel und Folge dieser Initiative ist keineswegs eine «Staatsmedizin» - wie im Artikel von Ignazio Cassis unterstellt wird.

Die Initiative gibt Bund und Kantonen keine neuen staatlichen Regelungskompetenzen, aber sie gibt dem Gesetzgeber klare Zielvorgaben und Impulse für die Neuausrichtung der Gesetzgebung. Dazu wird kein Gesetz für Hausarztmedizin notwendig sein. Hingegen sind die bereits bestehenden Gesetze im Bereich Aus- und Weiterbildung, Forschung, Berufsrecht und Krankenversicherungsrecht entsprechend anzupassen.

Die Formulierung «Bund und Kantone sorgen im Rahmen ihrer Zuständigkeiten für eine ausreichende, allen zugängliche, fachlich umfassende und qualitativ hochstehende medizinische Versorgung der Bevölkerung durch Fachärztinnen und Fachärzte der Hausarztmedizin» heisst nicht, dass der Staat dies alles «selber macht», sondern hiefür «im Rahmen seiner Zuständigkeiten» die erforderlichen Rahmenbedingungen schafft. An der bisherigen Aufgabenteilung zwischen Bund und Kantonen wird also mit Ausnahme geringfügiger Kompetenzverschiebungen zugunsten des Bundes nichts geändert.

Die Ärzte in freier Praxis sind zwar eigenverantwortliche Kleinunternehmer, aber in vielen Belangen durch die Abhängigkeiten und Obligatorien im Bereich der Sozialversicherung eingeschränkt und reguliert. Die Initiative möchte dies ändern, den freiberuflich tätigen Ärzten einen grösseren Handlungsspielraum einräumen und den Beruf der Hausärztin und des Hausarztes wieder attraktiver gestalten - nicht mehr und nicht weniger. Es ist zu hoffen, dass die Initiative eine grundsätzliche Diskussion über die Ausge- staltung der Gesundheitsversorgung in der Schweiz auslösen wird. Am Schluss wird die Bevölkerung darüber zu befinden haben. In welcher Weise und wann der Gesetzgeber dann konkret die Initiative umsetzen wird, liegt im Rahmen der Vorgaben grundsätzlich in dessen Kompetenz. Herr Cassis und seine Kolleginnen und Kollegen im Parlament werden es in der Hand haben, den befürchteten Gang Richtung Staatsmedizin zu verhindern. Die Initiative wird sie dabei unterstützen.

Vielleicht ist es nützlich, nochmals darauf hinzuweisen, dass keine der in der Initiative enthaltenen Kompetenzbestimmungen den Staat zu einem neuen oder zusätzlichen «Aktivismus» verpflichtet. Die Kompetenzen zur Legiferierung im Bereich der Medizin sind schon jetzt in der Bundesverfassung enthalten (namentlich in Art. 95, wonach der Bund Vorschriften erlassen kann über die Ausübung der privatwirtschaftlichen Erwerbstätigkeit, in Art. 63 und 64 über die Berufsbildung und die Forschung sowie in den Art. 117 und 118 über die Kranken- und Unfallversicherung und den Schutz der Gesundheit). Auf diese Verfassungsgrundlagen stützen sich das Medizinalberufegesetz, das Berufsbildungsgesetz, das Forschungsgesetz, das Kranken- und Unfallversicherungsgesetz, das Heilmittelgesetz usw. ab.

Der Initiativtext fügt sich somit ein in die bisherige Gesundheitsverfassung. Er verlangt keine revolutionäre Umgestaltung, nur eine bessere und ausgewogenere Grundversorgung durch die Hausarztmedizin. Das liegt im langfristigen Interesse der Öffentlichkeit, vor allem aber sollen ungerechtfertigte Privilegien und Verzerrungen im Gesundheitswesen korrigiert und ein Beitrag zur Kostenreduktion geleistet werden.

Am Ende seines Artikels spricht Ignazio Cassis von den negativen Auswirkungen einer Besserstellung der angestellten Ärzte auf die Freiberufler und von der Sozialisierung der Medizin durch das KVG. Er deutet dies als «entscheidenden Schritt in die Richtung des Aussterbens dieser Freiberufler». Unverhohlen und in Verkennung der Realitäten fügt er an: «Ist mit der Volksinitiative Ja zur Hausarztmedizin` das letzte Wort dazu bereits gesprochen?»

Das ist der falsche Ansatz. Die Initiative verpflichtet klar zu einer freiheitlichen Ordnung. Zudem bietet die Volksinitiative «Ja zur Hausarztmedizin», die am 1.4.2010 mit über 200000 Unterschriften eingereicht wurde, die einmalige Chance, den Stellenwert der Hausarztmedizin zu überdenken und zu verbessern jenseits aller interessenbezogenen Grabenkämpfe. 